\title{
Reflexões sobre a não-intervenção do Estado na "atividade econômica", nos termos do Art. 173 da vigente Constituição Federal
}

\author{
Ruy de Jesus Marçal Carneiro ${ }^{1}$
}

\begin{abstract}
Resumo
Cuida-se de analisar a Constituição Federal de 1988, no que diz respeito ao seu Título VII - "DA ORDEM ECONÔMICA E FINANCEIRA", tratando-se, mais especificamente, da não-intervenção do Estado na atividade econômica, posto que esta prerrogativa está mais voltada para a iniciativa privada, cabendo ao Poder Público federal, de forma extraordinária, aí envolver-se, quando se tratem de condições excepcionais, quais sejam, cuidar dos "imperativos da segurança nacional" e atender aos "relevantes interesses coletivos", situações em que o particular não há de demonstrar interesse mais efetivo, pois o seu móvel na área econômica é aquele em que esteja presente o lucro, enquanto que no âmbito das duas situações anteriores, como tais nominadas no Texto Maior, há de vicejar, primacialmente, o interesse público.
\end{abstract}

\section{Palavras-Chave:}

Todos sabem que a atual Constituição Federal traz estampada nas suas regras que a "atividade econômica" é para ser exercitada, preferencialmente, pelos particulares, devendo o Poder Público dela afastar-se, evitando que ocorra o que acontecia antes da promulgação do atual Texto vigente, onde o Estado de tudo participava, inclusive sendo proprietário até de atividades hoteleiras.

Isto fica muito claro ao se ler o contido no "Título VII" do Texto Constitucional, que trata da "Ordem Econômica e Financeira", quando diversos princípios voltados para essa realidade avultam firmemente. Assim é que o Art. 170 explicita no seu "caput" que:

\footnotetext{
A ordem econômica, fundada na valorização do trabalho humano e na livre iniciativa, tem por fim assegurar a todos existência digna, conforme os ditames da justiça social, observados os seguintes princípios.
}

Nesta linha de raciocínio, seguindo a esteira da citada dicção constitucional acima transcrita, verifica-se que, além de ter a livre iniciativa como um dos fundamentos da já

1 Mestre e Doutor em Direito Constitucional pela PUC/SP e Docente da Universidade Estadual de Londrina: Graduação em Direito, Especialização em Direito do Estado e do Programa de Pós-Graduação em Direito Negocial. 
comentada "ordem econômica", a principiologia trazida pelo mesmo dispositivo faz registrar, com intensidade, que a "livre concorrência"(Art. 170, IV) é fator determinante para o exercício de tal atividade neste País, além de prestigiar outros princípios, como, por exemplo, a "propriedade privada"(Art. 170, II), a "defesa do consumidor"(Art. 170, V), o "tratamento favorecido para as empresas de pequeno porte constituída sob as leis brasileiras e que tenham sua sede e administração no País"(Art. 170, IX). Vê-se, por conseguinte, que o particular é constitucionalmente prestigiado, valendo salientar, para reforçar o ponto, que o parágrafo único do dispositivo em comento fixa, fortemente, que:

É assegurado a todos o livre exercício de qualquer atividade econômica, independentemente de autorização de órgãos públicos, salvo nos casos previstos em lei.

Está, pois, definitivamente estampado na Lei Maior que não compete ao Poder Público, de quaisquer dos componentes da Federação brasileira, outro caminho senão o de afastar-se da "atividade econômica", que deve ser impelida e exercitada pelos particulares no âmbito da "livre iniciativa", pois esta é fundamento, tanto da República quanto do Estado Democrático de Direito, conforme encontra-se preceituado no corpo da Constituição Federal, tal como a seguir se transcreve:

Art. 1ㅇ - A República Federativa do Brasil, formada pela união indissolúvel dos Estados e Municípios e do Distrito Federal, constitui-se em Estado Democrático de Direito e tem como FUNDAMENTOS: [...] IV - os valores sociais do trabalho e da LIVRE INICIATIVA" - destacou-se -.

Com este apontamento, numa interpretação do sistema constitucional, aliando o seu primeiro dispositivo, de forma mais genérica, àquele do seu Art. 170, que fala da "Ordem Econômica e Financeira", particularizando-a, observa-se com clareza que a intenção do legislador constituinte foi a de dar um novo viés às atividades produtivas no Brasil. De um lado, afastando o Estado-empresário, com todas as mazelas que carrega no seu corpo dinossáurico, parafraseando, neste ponto, o Embaixador Roberto Campos, e, de outro, permitindo que a brasilidade, por intermédio dos seus empresários, possa fazer com que a Economia, mercê da "livre iniciativa", bem como da "livre concorrência", permita que o homem comum exercite a sua vocação nesse tão importante segmento social, que é a atividade empresarial. 
Poder-se-ia, noutro ponto, perguntar-se se o mercado seria, face aos apontamentos anteriores trazidos para este texto, o grande articulador desse processo, agindo livremente, descurando-se dos princípios éticos e tornando o meio empresarial uma selva onde reinaria o interesse pessoal de cada qual em prejuízo, por conseguinte, do homem-consumidor. Claro que não, pois se de um lado a "livre iniciativa" é um princípio de ordem constitucional, por outro, não há de esquecer-se que a "livre concorrência" é também componente de uma principiologia voltada para a já referida "Ordem Econômica e Financeira".

Verifica-se, ante o exposto, que se pode ter, em algum momento, a colidência principiológica de dois vetores constitucionais: a "livre iniciativa" e a "livre concorrência". Em razão disto, face aos valores que permeiam ambos os princípios constitucionalmente consagrados, é dever do Estado estar atento fiscalizando as condutas dos particulares e os caminhos trilhados pelas suas empresas. Tanto isto é verdade, que, atualmente, neste País, tem-se a participação ativa e diligente de um órgão do Poder Executivo, o qual se localiza no âmbito do Ministério da Justiça, que é o Conselho Administrativo de Defesa Econômica CADE.

Por diversas vezes, instado a manifestar-se, o fez de maneira incisiva e concludente, como, para registrar apenas um exemplo, no "affaire" da "aquisição da KOLYNOS do Brasil S/A, atual KOLYNOS do Brasil Ltda., pela Colgate-Palmolive Company, em decorrência de compra realizada no exterior, através(sic) de processo privado de leilão, no qual a ColgatePalmolive Company e sua subsidiária KAC Corporation adquiriram parte dos negócios mundiais de saúde bucal da American Home Products Corporation (AHP).".

Neste episódio, ficou assentado que se tratava de "ato de concentração econômica", razão pela qual tal feito foi submetido ao CADE, para que, no âmbito de sua competência, pudesse manifestar-se a respeito do tema e garantir o direito dos consumidores, mantendo-se o reinado das diç̧ões constitucionais, a fim de que o princípio constitucional da "livre concorrência" não se visse afrontado.

Cumprindo a sua obrigação funcional, a Conselheira Lucia Helena Salgado e Silva teve a oportunidade de trazer à colação, no seu relatório, que dele, aqui, é trazido um excerto, dados importantíssimos acerca dos formidáveis números que envolviam a citada transação comercial. 
Registrou a nominada Conselheira tratar-se de ato de concentração econômica, submetido ao CADE na forma do Art. 54 da Lei no 8.884, de 11 de junho de 1994, e que, por isto,

A Colgate-Palmolive Company, doravante denominada simplesmente COLGATE COMPANY, sediada nos EUA, mantém operações em mais de 75 países e exporta para mais de 100. Atua no segmento de higiene e limpeza, destacadamente higiene bucal, higiene pessoal, produtos para limpeza doméstica, cuidados com tecidos, bem como em segmentos da indústria de nutrição animal. É no segmento de higiene bucal (creme dental, escova dental, fio dental e enxaguante bucal) que a COLGATE COMPANY detém liderança mundial. Sendo a única empresa global voltada prioritariamente para a higiene bucal, a COLGATE COMPANY possui 47 fábricas de produtos de higiene bucal no mundo inteiro, número superior ao de qualquer concorrente. De acordo com as informações prestadas às fls.11 e 13, os negócios realizados em 1994 pela COLGATE COMPANY no segmento de higiene bucal foram da ordem de US\$ 2,4 bilhões, o que representa $24 \%$ do faturamento bruto mundial, estimado em US\$ 10 bilhões. Nos últimos cinco anos, a COLGATE COMPANY investiu cerca de US\$ 1,894 bilhão (excluída a operação KOLYNOS) em aquisições ou em joint-ventures, dos quais 19,61\% envolvem negócios de

higiene bucal (fls. 508, Apenso III). Nestes termos, é importante destacar que a aquisição da KOLYNOS representa o maior investimento realizado pelo Grupo, ou seja, 55\% dos investimentos realizados pela COLGATE COMPANY. A COLGATE COMPANY no Brasil opera através de suas subsidiárias C-P Têxtil Industrial Comércio Ltda. (100\%) e Colgate-Palmolive Ltda. (100\%), doravante denominada simplesmente COLGATE LTDA., que, por sua vez, detém 50\% da Dental Pack Ind. Comércio Ltda. e, no Uruguai, 100\% da Alexandria S.A. (fls. 245 a 246, Apenso III). Cabe ressaltar que a empresa Dental Pack Ind. Comércio Ltda., fabricante de tubos laminados usados como recipiente de cremes dentais, iniciou suas operações a partir de uma joint-venture entre COLGATE LTDA. E Itap Embalagens S.A., sendo sua produção vendida exclusivamente à COLGATE LTDA. Em 06/09/95, o CADE foi notificado da aquisição da Dental Pack Ind. Comércio Ltda. pela COLGATE LTDA. O valor da transação foi de US\$ 2,4 milhões (fls. 505, Apenso III). Em 1990, a COLGATE LTDA. adquiriu, por aproximadamente US\$ 11 milhões, a linha de produtos Pinho Sol, da Clorox Company".

Como se tratava de aquisição de uma empresa que fabricava os produtos "Kolynos", tão conhecidos da população brasileira, por parte de uma outra, a que fabricava os produtos "Colgate", também altamente do gosto dos consumidores, poder-se-ia antever que o mercado ficaria restrito a um só fabricante, com duas marcas de nomeada nas mãos, condição que poderia vir a dano dos consumidores e, por conseqüência, ferir o princípio constitucional da "livre concorrência"(Art. 170, IV).

Todavia, isto não ocorreu, já que houve a manifestação do organismo público responsável em evitar ofensa aos meios éticos nas atividades comerciais do País, respeitando, por conseguinte, as prescrições da Constituição Federal e de sua norma 
integradora, a Lei Nacional no 8.884, de 11 de junho de 1994, norma que, de acordo com o seu Art. 1으, "dispõe sobre a prevenção e a repressão às infrações contra a ordem econômica, orientada pelos ditames constitucionais de liberdade de iniciativa, livre concorrência, função social da propriedade, defesa dos consumidores e repressão ao abuso do poder econômico".

Assim, pois, o Estado veio e colocou cobro a tal anomalia, determinando, por intermédio do CADE, que na "natureza da concorrência do mercado de creme dental - por diferenciação de produto - tem na marca a sua principal arma", que era a tese havida na representação em comento, a seguinte decisão:

\begin{abstract}
A natureza da concorrência no mercado de creme dental - por diferenciação de produto - tem na marca a sua principal arma. A concorrência intermarcas, por meio da construção de reputação e laços de lealdade com o consumidor é a forma predominante assumida pela concorrência nesse mercado. De todo o exposto ao longo do voto, conclui-se que é o controle simultâneo das duas marcas mais importantes do mercado, em particular da marca dominante KOLYNOS, a barreira à entrada significativa e, por conseguinte, a fonte do poder de mercado agora detido pela adquirente. Assim, é sobre o controle de marcas que deve se concentrar a decisão deste Conselho. A empresa deverá suspender a utilização da marca KOLYNOS e extensões para a fabricação e comercialização de creme dental voltadas para o mercado interno pelo prazo de quatro anos ininterruptos, a contar da aprovação por este Conselho do plano de suspensão a ser apresentado pela empresa. Inclui-se na suspensão qualquer material de embalagem, propaganda e promoção relacionado à marca do produto creme dental. As extensões referidas nesta decisão são Kolynos Super Branco, Kolynos Ação Total, Kolynos Fresh, Kolynos Clorofila, Kolynos Anti-placa, Kolynos Star Gel, Kolynos Prevent, Kolynos Tandy, Kolynos Fluor2 Gel, Kolynos Bicarbonato de Sódio e todas as que pudessem ser criadas a partir da marca KOLYNOS.
\end{abstract}

Em outras palavras, aqui se encontra presente com a citada decisão o respeito

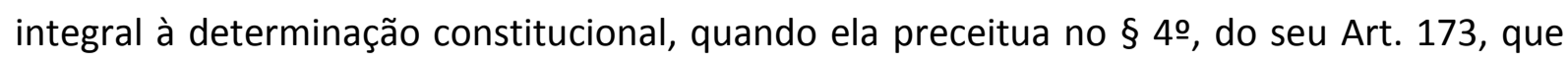
“A lei reprimirá o abuso do poder econômico que vise à dominação dos mercados, à eliminação da concorrência e o aumento arbitrário dos lucros".

O que se quis, nesta rápida notícia, era dar conta de que o Estado, mesmo devendo estar fora da exploração da "atividade econômica", não pode estar alheio às determinações da Constituição Federal, que o obriga a tutelar o interesse público e, nele, cuidar para que o seu administrado não fique à mercê da selvageria do mercado, sendo ele, o Estado, obrigado a obstaculizar tal prática. 
Por outro norte, mister é que se pergunte se este impedimento de que o Estado insirase na "atividade econômica" é de fato absoluto, ou se comporta algum temperamento na sua aplicação.

Sabe-se que o Estado deve ser prestador de muitos serviços públicos, que devem ser fruídos pela sociedade, a fim de que esta atinja, o que é dever dele próprio: o bemcomum de todos os componentes do tecido social.

Tais serviços públicos, bem assim as suas titularidades estão preconizadas no Texto Constitucional, ora adjudicando-se à União, ora aos Estados-Federados, ora aos Municípios, ora ao Distrito Federal. Cabe a tais entes federados a sua execução, ou não. Se for do seu interesse pode prestá-los diretamente; em não o sendo, isto pode ser feito pelo particular, respeitada a autorização legislativa, em cada caso, bem como os procedimentos licitatórios, a fim de que não se veja ferido o princípio da isonomia. Este é o jogo. Nas mãos do Poder Público, não se há de falar em lucro, mas tão só os meios para a sobrevivência do sistema; nas mãos do particular, que se transforma em agente público, sendo, como sua espécie, colaborador da Administração Pública em tal atividade, o lucro é o seu objetivo principal, quando executor de um serviço publico, cumprindo, por conseqüência, ao poder concedente, fazer com que este objetivo seja integralmente respeitado.

O que a Constituição Federal não permite é que o Poder Público, em quaisquer das esferas da Federação - União, Estados-Federados, Municípios e Distrito Federal -, insira-se na exploração da "atividade econômica", buscando o lucro, que é o objetivo de qualquer negócio. Não, aqui o Estado não deve intervir, tampouco participar de maneira ordinária, sob pena de o fazendo, constituir-se em ofensor, ele próprio, às regras constitucionais que deve respeitar e fazer respeitar, sem quaisquer meneios.

Vê-se, por isto, que, de acordo com o estabelecido na Constituição Federal, no seu Art. 173, § 1으. II, ainda dentro do "Título" da "Ordem Econômica e Financeira", o Estado, de forma extraordinária, pode participar da chamada "atividade econômica", fazendo-o, sempre, em igualdade de condições com os particulares, sem quaisquer privilégios, e por meio dos entes comerciais criados por si, cuja natureza jurídica é, ainda, apontada pelo Texto Constitucional. Neste ponto, é interessante deixar apontado o que registra o dispositivo anteriormente mencionado.

Assim preleciona a citada prescrição: 
A lei estabelecerá o estatuto jurídico da empresa pública, da sociedade de economia mista e de suas subsidiárias que explorem atividade econômica de produção ou comercialização de bens ou de prestação de serviços, dispondo sobre: [...] a sujeição ao regime jurídico próprio das empresas privadas, inclusive quanto aos direitos e obrigações civis, comerciais, trabalhistas e tributárias.

Verifica-se, por conseguinte, que o Estado só extraordinariamente pode envolverse com a "atividade econômica", para explorar atividade "de produção ou comercialização de bens ou de prestação de serviços". E se o fizer não terá quaisquer privilégios em relação às empresas privadas e, como dito pelo Texto Maior, haverá de sujeitar-se, também, às normas de direitos e obrigações civis, comerciais, trabalhistas e tributárias.

Nesta linha, por conseqüência, participará de tal mister por meio de entidades próprias, ou seja, por intermédio de sociedades de economia mista e de empresas públicas. E estas são aquelas apontadas pelo Decreto-Lei no 200, de 25 de fevereiro de 1967, que cuidou, ao tempo, de dispor sobre a organização da Administração Federal. Nesta trilha, o citado diploma legal conceituou o que fosse sociedade de economia mista e empresa pública. Para a primeira, no seu Art. 5으, III, grafou que se trata de "entidade dotada de personalidade jurídica de direito privado, criada por lei para a exploração da atividade econômica, sob a forma de sociedade anônima, cujas ações com direito a voto pertençam, em sua maioria, à União ou a entidade da administração direta". Relativamente à segunda, passou a registrar que é aquela que é, conforme pontua o mesmo Art. 5으, no seu inciso I, "dotada de personalidade jurídica de direito privado, com patrimônio próprio e capital exclusivo da União, criada por lei para exploração de atividade econômica que o Governo" (da União Federal) "seja levado a exercer por força de contingência ou de conveniência administrativa, podendo revestir-se de qualquer uma das formas admitidas em direito". Neste passo, pode-se entender, à dicção proposta, que mesmo a empresa pública poderá aparecer sob o figurino de entidade unipessoal.

Observa-se ao que anteriormente quedou-se registrado que ambas as formas de participação na "atividade econômica" por parte do Estado só se darão no âmbito da União, jamais nos demais entes federativos, embora isto ocorra ainda hoje, como herança havida das situações anteriores à promulgação do vigente Texto Constitucional. 
Um caminho que deve ser apontado, repetindo-se, sem quaisquer dúvidas, é que as figuras do Estado - sociedade de economia mista e/ou empresa pública - para intervir na "atividade econômica" não deverão ter qualquer privilégio, acredita-se, para não angustiar e sufocar a iniciativa privada, bem como o princípio da isonomia, sobretudo quando se sabe que o Tesouro Nacional com os seus investimentos poderá descompassar a concorrência, na exploração da economia, devendo, por via de tal raciocínio, sujeitarem-se, ambas as figuras empresariais, como bem diz o Decreto-Lei no 200, de 25 de fevereiro de 1967, "às normas de direitos e obrigações civis, comerciais, trabalhistas e tributários".

Se não deve haver quaisquer privilégios para ambos os entes estatais - sociedade de economia mista e empresa pública -, há, por outro norte, dificuldades para o desenvolvimento delas na mesma "atividade econômica". Isto fica claro quando se compulsa a Constituição Federal e lá se verificam alguns dispositivos que objetivam fazer com que o Poder Público e as suas entidades da administração indireta, como as duas já nominadas, submetam-se aos princípios constitucionais expressos que dirigem-se à Administração Pública.

É, pois, o que se lê no Art. 37, "caput", no capítulo próprio dirigido a esta mesma Administração Pública, que determina:

A administração pública direta e indireta de qualquer dos Poderes da União, dos Estados, do Distrito Federal e dos Municípios obedecerá aos princípios de legalidade, impessoalidade, moralidade, publicidade e eficiência.... - Destacou-se.

Por conta disto, verifica-se que tais entidades da administração indireta do Estado sociedades de economia mista e empresas públicas - devem estar submetidas às determinações da lei; devem tratar tudo com impessoalidade; devem ter os seus atos inteiramente publicizados e agirem com a maior eficiência. Assim, enquanto o particular pode fazer tudo o que a lei não proíbe, tais organizações só podem fazer o que a lei determina. Nesta trilha, verifica-se que o Estado, por meio de tais organizações, num mercado aberto, onde deve vicejar a livre concorrência e a iniciativa plena, como vetores de ordem constitucional, tem em seu desfavor a obrigação legal de que os seus empregados, posto que estão elas submetidas às relações trabalhistas, devam ser recrutados por meio de concursos públicos, que é o que não acontece com as suas concorrentes; devem adquirir 
bens e serviços pelos procedimentos licitatórios, sempre custosos quanto ao tempo em que se desenvolvem, manietando tais entes da administração indireta federal e, por conta disto, dificultando o seu processo concorrencial perante os demais que trabalham no mesmo campo de atividade. Grosso modo, poder-se-á lembrar, à guisa de registro, as dificuldades dos bancos estatais - Banco do Brasil S.A., por exemplo - na sua lida diária com os conglomerados particulares.

Claro está que tais registros são feitos relativamente às organizações estatais de que aqui se trata, criadas e existentes anteriormente à nova Constituição Federal, mas que, por passarem para a nova ordem constitucional deveriam submeter-se inteiramente às diç̧ões que ela, atualmente, aponta e quer ver respeitadas.

Após a promulgação da nova Lei Maior, o legislador constituinte entendeu de afastar o Estado da exploração da "atividade econômica", ou pelo menos minimizar a sua participação, permitindo que isto só ocorra em situações excepcionalíssimas.

Neste caminho, volte-se, agora, para o Art. 173, e os seus parágrafos e incisos, da Constituição Federal, que deixam afirmados que o Estado só intervirá na "atividade econômica" quando tiver de atender a duas exigências, contidas no referido Texto, que se pode entender sejam de profunda relevância para a sociedade brasileira: 1) "quando necessária aos imperativos da segurança nacional" e para atender 2) "a relevante interesse coletivo", bem como apresenta outras condições, quando o Estado se veja transformado em empresário exercitando, em toda a plenitude, a "atividade econômica". A diç̧ão é a que se segue:

Art. 173 - Ressalvados os casos previstos nesta Constituição, a exploração direta de atividade econômica pelo Estado só será permitida quando necessária aos imperativos da segurança nacional ou a relevante interesse coletivo conforme definidos em lei.

§ 10 - A lei estabelecerá o estatuto jurídico da empresa pública, da sociedade de economia mista e de suas subsidiárias que explorem atividade econômica de produção ou comercialização de bens ou de prestação de serviços, dispondo sobre $^{2}$ :

I - sua função social e formas de fiscalização pelo Estado e pela sociedade;

II - a sujeição ao regime jurídico próprio das empresas privadas, inclusive quanto aos direitos e obrigações civis, comerciais, trabalhistas e tributários;

$\S 1$ o com nova redação dada pela Emenda Constitucional no 19, de 04 de junho de 1998. Redação Anterior: "§ 10 - A empresa pública, a sociedade de economia mista e outras entidades que explorem atividade econômica sujeitam-se ao regime jurídico próprio das empresas privadas, inclusive quanto às obrigações trabalhistas e tributárias." 
III - licitação e contratação de obras, serviços, compras e alienações, observados os princípios da administração pública;

IV - a constituição e o funcionamento dos conselhos de administração e fiscal, com a participação de acionistas minoritários;

V - os mandatos, a avaliação de desempenho e a responsabilidade dos administradores.

§ 20 - As empresas públicas e as sociedades de economia mista não poderão gozar de privilégios fiscais não extensivos às do setor privado.

§ 3o - A lei regulamentará as relações da empresa pública com o Estado e a sociedade.

§ 40 - A lei reprimirá o abuso do poder econômico que vise à dominação dos mercados, à eliminação da concorrência e ao aumento arbitrário dos lucros.

§ 50 - A lei, sem prejuízo da responsabilidade individual dos dirigentes da pessoa jurídica, estabelecerá a responsabilidade desta, sujeitando-a às punições compatíveis com sua natureza, nos atos praticados contra a ordem econômica e financeira e contra a economia.

Com a transcrição havida e à sua análise, percebe-se, sem muita dificuldade, que dois óbices importantes são colocados para que o Estado venha a participar do mercado, mesmo que de forma extraordinária. Trata-se de que o legislador infraconstitucional, no âmbito de sua competência e por meio de uma simples lei ordinária, defina o que sejam: "imperativos da segurança nacional" e "relevante interesse coletivo". Após isto, aí sim, estará o Estado_apto, frise-se, mais uma vez, em condições de buscar "a exploração da atividade econômica",_nos precisos termos da dicção constitucional anteriormente registrada (Art. 173, "caput").

Porém, para tal desiderato, não fica só nisto, isto é, definir as duas questões postas pelo Texto Constitucional, mas, vai além, devendo o Poder Público buscar a criação da pessoa jurídica, que ficará responsável pela sua inserção na "atividade econômica", seja sociedade de economia mista e/ou empresa pública, sempre por meio de lei, lei esta que deverá atender a outros pressupostos constitucionais contidos no Art. 37, XIX, que aponta a necessidade de edição de lei específica, sem quaisquer penduricalhos, definindo, ainda, as áreas em que atuarão tais entes da administração indireta do Estado. A seguir, para compreensão da extensão do modal constitucional, transcreve-se a supra citada disposição, que assim aparece:

Art. 37 - A administração pública direta e indireta de qualquer dos Poderes da União, dos Estados, do Distrito Federal e dos Municípios obedecerá aos princípios 
de legalidade, impessoalidade, moralidade, publicidade e eficiência e, também, ao seguinte ${ }^{3}$ :

$[\ldots]$

XIX - somente por lei específica poderá ser criada autarquia e autorizada a instituição de empresa pública, de sociedade de economia mista e de fundação, cabendo à lei complementar, neste último caso, definir as áreas de sua atuação;

Numa análise sistemática da Constituição Federal, observa-se que a intenção do legislador constituinte não foi outra senão pretender que o particular, alicerçado na sua livre iniciativa, que é, agora, a um só tempo 1) fundamento da República e do Estado Democrático de Direito e 2) princípio constitucional, na ordem econômica e financeira, fosse o principal agente responsável pelo desenvolvimento da "atividade econômica" neste País.

Por fim, o objetivo deste pequeno estudo foi o de demonstrar o verdadeiro valor que têm para a sociedade brasileira os seus nacionais, ou "os estrangeiros residentes no País", pois dignificando-os quando do seu exercício nos meios econômicos, sejam quais forem, estará, de forma igual, a respeitar a "dignidade da pessoa humana", que, também, e "por essa razão, constitui o pressuposto básico de todo o ordenamento jurídico", na feliz assertiva de Miguel Reale. Por igual, ela, da mesma forma, fundamento tanto do Estado Democrático de Direito quanto da República Federativa do Brasil, permitindo que cada qual possa estimular a sua criatividade e praticar a livre iniciativa, visando ao bem-comum e, por conseqüência, ativar a economia nacional sem os percalços e as mazelas do abuso do poder econômico, com respeito à livre concorrência, Cabendo registrar, na hipótese de que isto não ocorra, de que deverá haver, com toda a intensidade, a participação estatal fiscalizadora, para prevenir e reprimir, por meio dos seus organismos competentes, as infrações contra a ordem econômica, em benefício, sempre, da sociedade brasileira.

3 art. 37 com nova redação dada pela Emenda Constitucional no 19, de 04 de junho de 1998. Redação Anterior: "Art. 37 - A administração pública direta, indireta ou fundacional, de qualquer dos Poderes da União, dos Estados, do Distrito Federal e dos Municípios obedecerá aos princípios de legalidade, impessoalidade, moralidade, publicidade e, também, ao seguinte:" 
Revista de Direito Público, LondRinA, V. 1, N. 1, P. 193-204, JAN./ABR. 2006. 